\title{
Sanat Eğitimi Dersi Alan Öğretmen Adaylarının Sanat Kavramına İlişkin Sahip Oldukları Algıların Metaforlar Aracılığıyla İncelenmesi
}

\section{Examining, Through Metaphors, The Perceptions Of The Art Term Of The Prospective Teachers Who Take Art Education Course}

Yahya Hiçyılmaz, ${ }^{\text {a* }}$ Yahya Adanır ${ }^{\mathrm{b}}$

${ }^{a}$ Dr. Öğr. Üyesi, Van Yüzüncü Y1l Üniversitesi Eğitim Fakültesi, Güzel Sanatlar Eğitimi, Van/Türkiye ORCID: 0000-0003-3453-9998

'Öğr. Gör., Muş Alparslan Üniversitesi, Rektörlük, 49250, Muş/Türkiye.

ORCID: 0000-0003-2915-2334

\section{MAKALE BILLGISİ}

\section{Makale Geçmişi:}

Başvuru tarihi: 20 Eylül 2018

Düzeltme tarihi: 21 Ekim 2018

Kabul tarihi: 08 Kasım 2018

\section{Anahtar Kelimeler:}

Sanat kavramı

Metafor

Sanat eğitimi

Algi

\section{ÖZ}

Bu araştırmanın amacı; sınıf öğretmenliği ve okul öncesi öğretmenliği bölümünde sanat eğitimi dersi alan öğretmen adaylarının "sanat" kavramına yönelik algılarını belirlemektir. Araştırmanın çalışma grubu, 2017-2018 eğitim öğretim yılı bahar döneminde Muş Alparslan Üniversitesi Eğitim Fakültesi bünyesinde sanat eğitimi dersi alan 2. ve 3. sınıflarda öğrenim gören toplam 100 öğretmen adayından oluşmaktadır. Veri toplamak amacıyla "Sanat... gibidir; çünkü..." şeklinde görüşme formu hazırlanmıştır. $\mathrm{Bu}$ doğrultuda toplanan nitel veriler içerik analizi yöntemi kullanılarak analiz edilmiştir. Bu analizler sonucunda 7 farklı tema belirlenmiştir. Bu temalar; özgürlüğün bir simgesi olarak sanat, yaratıcılığın bir ifadesi olarak sanat, duyguların bir ifade aracı olarak sanat, yönlendirici, eğitici ve öğretici yönüyle sanat, hazın bir kaynağı olarak sanat, yaşamın bir parçası olarak sanat ve yansıtıcı bir özellik olarak sanat şeklinde isimlendirilmiştir. Buna bağlı olarak öğretmen adaylarının oluşturdukları metaforlar temel alındığında, sanat kavramının birden fazla ve farklı metaforlarla açıklandığı görülmüştür.

\section{A B S T R A C T}

The purpose of this research is to determine the perceptions of the "art" term of the prospective teachers who take art education course in the elementary education and early childhood education. The study group consists of a total of 100 teacher candidates who are studying in the 2nd and 3rd classes of art education course in Muş Alparslan University Faculty of Education in the spring semester of 2017-2018 academic year. In order to collect data, an interview form as "Art is like a/an ..., because ..." was prepared. Qualitative data collected in this direction were analyzed using content analysis method. As a result of these analyzes, 7 different themes were determined. These themes are classified as; art as a symbol of freedom, art as an expression of creativity, art as a means of expressing emotion, art as a means of directing, educating and teaching, art as a source of pleasure, art as a part of life and art as a reflective feature. Accordingly, based on the metaphors of the prospective teachers, the concept of art has been revealed with multiple and different metaphors.

\section{Giriş}

Yaşamımızın bir parçası haline gelen sanat, insan hayatının her döneminde varlığını sürdürmüştür. Sanat, tarih öncesi dönemde mağaralarda yaşayan insanların yaptıkları ilkel resimlerden 21. yüzyılın modern sanatına kadar uzanan kültürel hareket tarihinin tamamını kapsar. Dolayısıyla sanat değişime açık bir olgu olarak ifade edilebilir.

Sanat toplumun yapısını bize yansıtır. Bu bakımından sanat zaman içerisinde kültürel gelişim ve sosyal bağlama göre değişir (Agyeman, 2015). Bu bağlamda tarih boyunca sanatın tanımı üzerine farklı yorumlamalara yer verilmiştir. Tolstoy

\footnotetext{
* Sorumlu yazar/Corresponding author e-posta: yahya-04@windowslive.com
} 
(1995) sanat, yaratıcılığın ve hayal gücünün etkileşimi ile elde edilen estetik sonuçtur şeklinde ifade etmiştir.

Sanat eserlerinin amacı sanatçıların duygularını yansıtması ve temsil etmesidir. $\mathrm{Bu}$ açıdan sanatçılar duygu ve düşüncelerini izleyiciye iletme özgürlüğünü sağlayan araç ve materyalleri seçerler (Christodoulou ve Styliaras, 2008). Sanatta araç ve gereçlerin değişmesi başka bir deyişle sanatın biçimlerinin değişmesiyle birlikte izleyicilerin beklentilerinin de değiştiği ileri sürülebilir. $\mathrm{Bu}$ bağlamda sanat, günümüzde farklı tanımlarla ortaya çıkan bir kavram haline gelmiştir.

Sanat eserlerini görsel metafor olarak değerlendiren fikirler bulunmaktadır (Bulut Kılıç ve Altıntaş, 2016). Özellikle resim sanatı bir çok biçimde görsel metaforik anlatım olarak karşımıza çıkmaktadır (Parsons, 2010). Metafor kelimesi etimolojik yapısı "birleşik kelime (meta+ phora) olarak izah edilen "metaphora" "ya dayanır. "Meta", "öte" anlamına gelen, "pgora" ise "taşımak" anlamını çağrıştıran Yunanca kökenli kelimelerdir" (Kılcan, 2017 s.13). Metafor, fikirler arasında bağlantı kurmak soyut fikirleri açıklamak veya duyguları iletmenin dolaylı ve güçlü bir yol olarak kabul edilir. İnsanların metafor kullanımlarını incelemek, onların duygularını ve tutumlarını açıkça belirlememize yardımcı olur (Cameron ve Maslen, 2010).

Eğitim sürecinin tamamlayıcı bir unsuru olan sanat eğitimi, sanatçı yetiştirmeye yönelik bir eğitim değildir. Daha çok bireyin sanat yoluyla eğitimi yani bireyin estetik eğitimi ile ilgilenmesidir. Bu açıdan okulöncesinden üniversite düzeyine kadar verilmesi gereken eğitim alanlarından biri olmaya devam edecektir (Özsoy, 2003). Bu bağlamda sanat eğitimi dersi alan öğretmen adaylarının sanat kavramına yönelik algılarının incelenmesi onların sanat eğitimine ilişkin düşüncelerini, bakış açılarını ve tutumlarını açıkça belirlememize yardımcı olur. Öğretmen adaylarının sanat kavramına ilişkin algılarını ortaya konulmasında etkili yollardan biri de öğretmen adaylarının bu kavrama ilişkin geliştirdikleri metaforlardır. Bireyler genellikle fikirlerini, inançlarını ve bilgilerini iletmek için metafor kullanırlar (Hamilton, 2016). Bireylerin yansittığı metaforlar bize düşünceleri hakkında tutarlı cevaplar verir (Cameron, 2003). Eğitim ortamında metaforların kullanılması bireylerin ele alınan kavramların karşılaştırma, ilişkilendirme görselleştirme ve yorumlama gibi süreçlerde zihinde organize edilerek öğrenilmesini kolaylaştırabilir. Aynı zamanda öğrenilen kavram hakkında görsel bir imaj sağlar. Bu çerçevede sınıf öğretmenliği ve okulöncesi öğretmenliği bölümünde sanat eğitimi alan öğretmen adaylarının "sanat" kavramına yönelik algılarının metaforlar yoluyla belirlenmesi amaçlanmıştır.

Literatürde, öğretmen adaylarının belirli konular hakkındaki metaforik algıları üzerinde birçok çalışma ile karşılaşılabilir. Sanat eğitimi (Akdeniz ve Çakırcı, 2017), sanat eğitimi dersi (Kalyoncu, 2013) gibi kavramların dışında farklı kavramları konu alan ve metaforik olarak analiz etmeyi amaçlayan çalışmalarda yapılmıştır (Buchanan, 2015; Eren ve Tekinarslan, 2012; Ekici ve Gökmen, 2014; Bilge, ve Erdogan, 2010; Geçit ve Geçer, 2011; Hamarat, 2016; Hamilton, 2016; Nartgün ve Özen, 2015; Seyitoğlu ve Çakar, 2017; Yılmaz, Göçen ve Yılmaz, 2013). Ancak sanat eğitimi dersi alan öğretmen adaylarının sanat kavramına ilişkin metaforik algılarını belirleyen bir çalışmaya rastlanmamıştır. Dolayısıyla bu çalışmanın literatüre olumlu yönde katkı sağlayabileceği söylenebilir.

\section{Yöntem}

$\mathrm{Bu}$ çalışmada, nitel araştırma türlerinden "fenomenoloji" deseni kullanılmıştır. Fenomenoloji deseni, bize tümüyle yabancı olmayan farkında olduğumuz ancak tam anlamıyla ayrıntılı bir anlayışa sahip olamadığımız olguları araştırmayı amaçlayan çalışmalar için uygun bir araştırma zemini oluşturur (Yıldırım ve Şimşek, 2013).

\section{1. Çalışma Grubu}

Araştırmanın çalışma grubu, 2017-2018 eğitim öğretim yılı bahar döneminde Muş Alparslan Üniversitesi Eğitim Fakültesi bünyesinde Sınıf Öğretmenliği ve Okul Öncesi programı kapsamında sanat eğitimi dersi alan 2. ve 3. sınıflarda öğrenim gören toplam 100 öğretmen adayından oluşmaktadır. Çalışma grubunun \%46's1 okulöncesi öğretmenliği programında, \%54'ü ise sınıf öğretmenliği programında öğrenim gören öğretmen adaylarından oluşmaktadır. Öğretmen adaylarının $\% 51$ 'i erkek ve \%49'u kadındır.

\subsection{Veri Toplama Arac1}

Öğretmen adaylarının sanat kavramına ilişkin sahip oldukları algıları belirlemek amacıyla "Sanat...gibidir; çünkü..." şeklinde görüşme formu hazırlanmıştır. Görüşme formunda boş bırakılan yerlerde yalınızca bir metafor kullanmaları ve bu metaforu tercih etmelerinin nedenlerini yazmaları istenmiştir. $\mathrm{Bu}$ doğrultuda doldurulan görüşme formları, araştırmanın temel veri kaynağı olarak kabul edilmiştir.

\subsection{Verilerin Analizi}

Araştırmada elde edilen nitel veriler içerik analizi yöntemi kullanılarak analiz edilmiştir. İçerik analizi; verilerin kodlanması, temaların bulunması, kodların ve temaların düzenlenmesi, bulguların tanımlanması ve yorumlanması şeklinde belirtilen dört aşama halinde gerçekleştirilir (Yıldırım ve Şimşek, 2013).

Veriler analiz edilmeden önce, toplanan verilerin belirlenen kavram çerçevesinde doldurulup doldurulmadığı kontrol edilmiştir. $\mathrm{Bu}$ bağlamda 10 adet form belirlenen yönerge çerçevesinde doldurulmadığından araştırma kapsamı dışına bırakılmıştır. Görüşme formunu dolduran öğretmen adaylarının gerçek kimlikleri gizli tutulmuştur. Erkek öğretmen adaylar EÖA1, EÖA2, kadın öğretmen adaylar KÖA1, KÖA2 şeklinde formüle edilmiştir. Daha sonra öğretmen adayları tarafindan verilen ifadeler incelenerek kodlar oluşturulmuştur. Her bir kod bir metafor olarak kabul edilmiştir. Kodlar birbirleri ile ilişkilendirilerek 7 farklı tema belirlenmiştir. Bir sonraki aşamada, araştırmanın güvenirliğini sağlamak amacıyla elde edilen metaforların temaları temsil edip etmediğini belirlemek amaciyla iki uzman görüşüne başvurulmuştur. Metaforların ve temaların içinde olduğu bir liste oluşturulmuştur. Söz konusu bu listede kodların temalarile eşleştirilmesi istenmiştir. Karşılaştırma güvenirliğini sağlamak amacıyla Miles ve Huberman, (2015) tarafından öne sürülen güvenirlik formülü kullanılmıştır. Buna göre, Güvenirlik=Görüş Birliği/Görüş Birliği + Görüş Ayrılığ1 şeklinde hesaplanmıştır. Bu doğrultuda uzmanlar arasındaki görüş birliğinin \% 90 düzeyinde olduğu görülmüştür. Farklı biçimde eşleşen kod ve temalar tartışılarak uzlaşma yoluyla 
kod ve temalar oluşturulmuştur. İlgili temalar altında toplanan kodların frekans ve yüzde değerleri alınarak değerlendirilmiştir.

\section{Bulgular ve Yorumlar}

Çalışma grubunu oluşturan 100 öğretmen adayı, sanat kavramına yönelik birbirinden faklı 40 metafor geliştirmişledir. $\mathrm{Bu}$ metaforlar ortak özellikler bakımından 7 faklı tema altında incelenmiştir. Bu temalar; özgürlügüün bir simgesi olarak sanat, yaratıcılığın bir ifadesi olarak sanat, duygusal bir ifade aracı olarak sanat, yönlendirici, eğitici ve öğretici yönüyle sanat, hazın bir kaynağı olarak sanat, yaşamın bir parçası olarak sanat, yansıtıcı bir özellik olarak sanat şeklindedir. Her bir temayı temsil ettiği düşünülen metaforlara ilişkin bilgilere yer verilmiştir. Ayrıca öğretmen adaylarının geliştirdikleri metaforlar için örnek ifadelere yer verilmiştir. Öğretmen adaylarının sanat kavramına yönelik geliştirdikleri metaforların temalara göre dağılımları Tablo 1'de gösterilmiştir.

Tablo 1. Öğretmen Adaylarının Sanat Kavramına İlişkin Geliştirdikleri Metaforların Temalara Göre Dağılımları

\begin{tabular}{|c|c|c|c|c|c|}
\hline Temalar & Metafor & $\begin{array}{l}\text { Cinsiyet } \\
\text { Erkek }\end{array}$ & Kadin & $\mathrm{f}$ & $\%$ \\
\hline \multirow{6}{*}{$\begin{array}{l}\text { Özgürlüğün bir } \\
\text { simgesi olarak } \\
\text { sanat }\end{array}$} & Kuş & 1 & 1 & 2 & 2 \\
\hline & Okyanus & - & 1 & 1 & 1 \\
\hline & Deniz & 1 & 1 & 2 & 3 \\
\hline & Gökyüzü & - & 3 & 3 & 3 \\
\hline & Ruh & 1 & - & 1 & 1 \\
\hline & Y1ldiz & 1 & - & 1 & 1 \\
\hline \multicolumn{2}{|l|}{ Toplam } & 4 & 6 & 10 & 10 \\
\hline \multirow{9}{*}{$\begin{array}{l}\text { Yaratıcılığın } \\
\text { bir ifadesi } \\
\text { olarak sanat }\end{array}$} & İnsan & 8 & 10 & 18 & 18 \\
\hline & Hayal & 1 & 2 & 3 & 3 \\
\hline & Gökkuşağ1 & 2 & 2 & 4 & 4 \\
\hline & Bukalemun & 1 & 1 & 2 & 2 \\
\hline & Kapalı kutu & - & 1 & 1 & 1 \\
\hline & Dil & 1 & - & 1 & 1 \\
\hline & Renk & - & 1 & 1 & 1 \\
\hline & Gölge & - & 1 & 1 & 1 \\
\hline & Boş kâğıt & - & 1 & 1 & 1 \\
\hline Toplam & & 13 & 19 & 32 & 32 \\
\hline \multirow{4}{*}{$\begin{array}{l}\text { Duygusal bir } \\
\text { ifade aracı } \\
\text { olarak sanat }\end{array}$} & Anne & - & 3 & 3 & 3 \\
\hline & Aşk & 2 & 3 & 5 & 5 \\
\hline & Yalnızlık & - & 1 & 1 & 1 \\
\hline & Huzur & 1 & - & 1 & 1 \\
\hline Toplam & & 3 & 7 & 10 & 10 \\
\hline \multirow{4}{*}{$\begin{array}{l}\text { Yönlendirici, } \\
\text { eğitici ve } \\
\text { öğretici } \\
\text { yönüyle sanat }\end{array}$} & Güneş & 2 & 1 & 3 & 3 \\
\hline & Öğretmen & 2 & 1 & 3 & 3 \\
\hline & Pusula & - & 1 & 1 & 1 \\
\hline & Öğrenci & 2 & 1 & 3 & 3 \\
\hline \multirow[t]{2}{*}{ Toplam } & & 6 & 4 & 10 & 10 \\
\hline & Çikolata & 5 & 2 & 7 & 7 \\
\hline Hazın bir & Kahve & 1 & - & 1 & 1 \\
\hline kaynağı olarak & Yemek & 1 & - & 1 & 1 \\
\hline sanat & İlaç & 1 & - & 1 & 1 \\
\hline Toplam & & 8 & 2 & 10 & 10 \\
\hline
\end{tabular}

\begin{tabular}{lllll}
\hline Kan & - & 1 & 1 & 1 \\
Zaman & - & 1 & 1 & 1 \\
Su & 1 & - & 1 & 1
\end{tabular}

\begin{tabular}{|c|c|c|c|c|c|}
\hline \multirow{4}{*}{$\begin{array}{l}\text { Yaşamın bir } \\
\text { parçası olarak } \\
\text { sanat }\end{array}$} & Nehir & 2 & - & 2 & 2 \\
\hline & Göz & - & 1 & 1 & 1 \\
\hline & Doğa & 6 & 4 & 10 & 10 \\
\hline & Kâinat & 3 & - & 3 & 3 \\
\hline \multirow[t]{3}{*}{ Toplam } & & 12 & 7 & 19 & 19 \\
\hline & Hayat & 2 & - & 2 & 2 \\
\hline & Filim & 1 & - & 1 & 1 \\
\hline \multirow{4}{*}{$\begin{array}{l}\text { Yansitıcı bir } \\
\text { özelik olarak } \\
\text { sanat }\end{array}$} & Futbol & 1 & - & 1 & 1 \\
\hline & Deneyim & 1 & - & 1 & 1 \\
\hline & Ayna & - & 3 & 3 & 3 \\
\hline & Ay & - & 1 & 1 & 1 \\
\hline Toplam & & 5 & 4 & 9 & 9 \\
\hline
\end{tabular}

Tablo 1 incelendiğinde kadın ve erkek öğretmen adaylarının en çok insan (\%18), doğa (\%10) ve çikolata (\%7) gibi metaforlar kullandıkları görülmüştür. Tablo incelenmeye devam edildiğinde, yaratıcılığın bir ifadesi olarak sanat şeklindeki temanın öğretmen adayları tarafından en fazla metaforla (\%32) ifade edildiği görülmektedir. Aynı zamanda yaşamın bir parçası olarak sanat şeklindeki temanın metaforların \%19'u ile ifade edildiği ve özgürlüğün bir simgesi olarak sanat, duygusal bir ifade aracı olarak sanat, yönlendirici, eğitici ve öğretici yönüyle sanat, hazın bir kaynağı olarak sanat şeklindeki temaların ise metaforların $\% 10$ 'u ile ifade edildiği belirlenmiştir. Bununla birlikte en az metaforla ifade edilen temanın ise yansıtıcı bir özellik olarak sanat (\%9) şeklindeki tema olduğu görülmüştür.

Tablo 1'de değinilen tema ve metaforlarla ilgili öğretmen adaylarının ifadelerinden doğrudan alıntılara aşağıda yer verilmiştir.

\section{1- Özgürlüğün Bir İfade Aracı Olarak Sanat}

$\mathrm{Bu}$ tema incelendiğinde, öğretmen adaylarının sanatçıların sonsuz konu seçimine sahip olabileceği üzerinde durduğu görülmüştür. Ayrıca sanatçıların konuları işleme biçimlerinde özgürce davrandıkları dile getirilmiştir. $\mathrm{Bu}$ bağlamda öğretmen adaylarının sanat kavramını özgürlüğün bir ifade aracı olarak algıladıkları şeklinde yorumlanabilir. Öğretmen adayları bu tema ile ilgili; kuş, okyanus, deniz, gökyüzü, ruh, yıldız şeklinde metaforlar geliştirmişlerdir. Aşağıda üretilen metaforlara ilişkin birkaç örnek verilmiştir.

"Sanat, gökyüzünde süzülen kuşlar gibidir. Çünkü gökyüzünde süzülen kuşlar özgürlerdir. İstedikleri her yere gidebilirler" (KÖA19).

"Sanat, sonu olmayan bir okyanus gibidir. Çünkü derinlere daldıkça sanatçılar gördükleri yeni şeyleri istedikleri şekilde işleyebilirler” (KÖA6).

"Sanat gökyüzü gibidir. Çünkü sanatçı sonsuzluğun içinde istediği konuyu seçebilir" (KÖA12).

\section{2- Yaratıcılığın Bir İfadesi Olarak Sanat}

Bu tema incelendiğinde, öğretmen adaylarının sanatçıların ele aldığı farklı konuları ve bu konuları işleme biçimi bakımında özgün davrandıkları üzerinde durdukları görülmüştür. $\mathrm{Bu}$ bağlamda ele alınan metaforlar doğrultusunda her bir sanat çalışmasının yaratıcı bir ürün olarak düşünüldüğü şeklinde yorumlanabilir. Bu tema ile ilgili öğretmen adayları; insan, hayal, gökkuşağı, bukalemun, kapalı kutu, dil, renk, gölge, boş kâğıt şeklinde metaforlar geliştirmişlerdir. Bu metaforlar birbirileri ile ilişkilendirilerek "yaratıcılığın bir ifadesi olarak sanat" şeklinde isimlendirilmiştir. Aşağıda üretilen metaforlara ilişkin birkaç örnek verilmiştir. 
"Sanat insan gibidir. Cünkü sanat biriciktir. Tıpkı insanlar gibi aynı özellikte başka bir benzeri yoktur. Hem psikolojik olarak hem de fizyolojik olarak birbirlerinden farklıdır” (EÖA3).

"Sanat gökkuşağ1 gibidir. Çünkü güzel renkler bir araya gelerek güzel bir görünüm sağladığı gibi sanatta da renkler bir araya gelerek güzel bir görünüm sağlayabilir (KÖA27).

"Sanat hayal gibidir. Çünkü sanat yoluyla hayalimizdekileri dilediğimiz şekilde sunabiliriz” (EÖA5).

“Sanat bukalemun gibidir. Çünkü sanat eseri özgünlüğün ve farklılığın ta kendisidir. Her renge bürünebilir" (EÖA87).

\section{3- Duygusal Bir İfade Aracı Olarak Sanat}

$\mathrm{Bu}$ tema incelendiğinde, öğretmen adaylarının sanat eserlerin sanatçıların duygularını ifade edebileceği bir araç olarak algıladıkları görülmüştür. Bu algıların; anne, aşk, yalnızlık, huzur gibi çeşitli metaforlar olduğu belirlenmiştir. Buradan hareketle bu tema "duygusal bir ifade aracı olarak sanat" şeklinde isimlendirilmiştir. Aşağıda üretilen metaforlara ilişkin birkaç örnek verilmiştir.

"Sanat anne gibidir. Çünkü annenin çocuğuna verdiği sevgi gibi sanat da bize benzer bir duygu verir" (EÖA26).

"Sanat aşk gibidir. Çünkü sanat aşk gibi kendisinde farklı duygular barındırır. Ruhu canlandırır” (KÖA33).

"Sanat huzur gibidir. Çünkü sanat eserleri bizi mutlu hissettiren bir ruha getirir" (EÖA9).

\section{4- Yönlendirici, Eğitici ve Öğretici Yönüyle Sanat}

$\mathrm{Bu}$ tema incelendiğinde, öğretmen adaylarının sanatın insan davranışları üzerinde yönlendirici ve eğitici bir yönü olduğu yönünde görüşler dile getirdikleri görülmüştür. Bu görüşlerin; güneş, öğretmen, pusula ve öğrenci gibi metaforlar olduğu belirlenmiştir. Bu bağlamda bu tema "yönlendirici, eğitici ve öğretici yönüyle sanat” şeklinde isimlendirilmiştir. Aşağıda üretilen metaforlara ilişkin birkaç örnek verilmiştir.

"Sanat öğretmen gibidir. Çünkü öğretmen öğrencilerini yönlendirdiği gibi sanat da izleyicileri yönlendirir (EÖA16).

"Sanat bir pusula gibidir. Çünkü insanlara yol gösterir" (EÖA80).

"Sanat öğrenci gibidir. Çünkü öğrencide sanat gibi şekillenir" (KÖA2).

\section{5- Hazın Bir Kaynağı Olarak Sanat}

$\mathrm{Bu}$ tema incelendiğinde, öğretmen adaylarının sanatı insanların tat alma ve rahatlama şeklindeki haz alma yönüne benzettiği görülmüştür. $\mathrm{Bu}$ benzetmeler çikolata, kahve, yemek ve ilaç gibi metaforlarla yapılmıştır. Dolayısıyla bu metaforlar "hazın bir kaynağı olarak sanat" olarak adlandırılan tema altına yerleştirilmiştir. Aşağıda üretilen metaforlara ilişkin birkaç örnek verilmiştir.

"Sanat çikolata gibidir. Çünkü çikolata yediğim zaman azda olsa bana farklı bir mutluluk verir. Dolayısıyla kendimi mutlu hissederim. Sanatı da bu şekilde anlatabilirim" (EÖA13).

"Sanat yemek gibidir. Çünkü yemekten nasıl haz alıyorsan sanat da öyledir" (KÖA17).

"Sanat ilaç gibidir. Çünkü rahatsız olan insanları ilaç nasıl rahatlatıyorsa sanat da ruhu rahatlatır" (KÖA43).

\section{6- Yaşamın Bir Parçası Olarak Sanat}

$\mathrm{Bu}$ tema incelendiğinde, öğretmen adaylarının sanatı insan vücudunda, doğada veya insan yaşamında gerekli olan unsurlara benzettikleri görülmüştür. Dolayısıyla bu tema "yaşamın bir parçası olarak sanat" şeklinde isimlendirilmiştir. $\mathrm{Bu}$ tema ile ilgili öğretmen adayları; kan, zaman, su, nehir, göz, doğa ve kâinat gibi metaforlar geliştirmişlerdir. Aşağıda üretilen metaforlara ilişkin birkaç örnek verilmiştir.

"Sanat kan gibidir. Çünkü insan vücudunda kan olmadan yaşanması mümkün değilse sanatsız bir toplumda yaşayamaz. Sanat toplumu besler" (KÖA29).

Sanat bir nehir gibidir. Çünkü nehir doğanın ayrılmaz bir parçası olarak yer alıyorsa sanat da toplumun ayrılmaz bir paçasıdır (EÖA95).

"Sanat su gibidir. Çünkü suyun insan dahil bütün canlıların vazgeçilmez bir parçası olduğu bilinmektedir. Bu yönüyle su sanata benzetilebilir" (KÖA9).

\section{7- Yansıtıcı Bir Özellik Olarak Sanat}

Bu tema incelendiğinde, öğretmen adaylarının sanatı öğrenme veya deneme yanılma sonucunda tasarlanan bir şeyin hayata geçirilen özelliklere veya direk yansıtma özeliği olan unsurlara benzetme yaptıkları görülmüştür. $\mathrm{Bu}$ benzetmeler; hayat, filim, futbol, deneyim, ayna, ay şeklindeki metaforlarla yapılmıştır. Dolayısıyla bu metaforlar "yansıtıcı bir özelik olarak sanat" olarak adlandırılın tema altında yerleştirilmiştir. Aşağıda üretilen metaforlara ilişkin birkaç örnek verilmiştir.

"Sanat ayna gibidir. Çünkü ayna her şeyi yansıta biliyorsa sanat da insandaki düşünceleri ve duygular yansıtır" (KÖA65).

Sanat filim gibidir. Çünkü filim sanat gibi yönetmenin hayal dünyasındaki yansımalarıdır. (EÖA50)

\section{Tartışma, Sonuç ve Öneriler}

Sanat eğitimi dersi alan öğretmen adaylarının "sanat" kavramına ilişkin sahip oldukları algıları metaforlar aracılığıyla incelemeyi amaçlayan bu araştırmada 40 adet metafor elde edilmiştir. Öğretmen adaylarının en çok kullandıkları metaforların insan (\%18), doğa (\%10) ve çikolata (\%7) olduğu görülmüştür. Sonuç olarak öğretmen adayları, "Sanat" kavramını birçok metafor ile tanımlamaktadır. Buradan hareketle öğretmen adaylarının "Sanat" kavramını daha çok yaratıcılık, haz, yaşamın bir parçası şeklinde algıladıkları söylenebilir.

Yaratıcılık, alışılmışın dışında özgün bir düşünce veya eylem olarak tanımlanır (Artut, 2013). Metaforlar bireylerin düşüncelerini, duygularını veya tutumlarını belirlemede önemli bir yol kabul edilir (Cameron ve Maslen, 2010). Bu bağlamda öğretmen adaylarının "sanat" kavramını daha çok yaratıcılıkla ilişkilendirerek düşüncelerini ifade ettikleri görülmüştür. Yaratıcılığın bir ifadesi olarak sanat şeklinde tanımlanan temanın metafor çeşitliliğin daha fazla olduğu gözlemlenmiştir. Dolayısıyla öğretmen adaylarının "sanat" kavramını daha çok bir ürün olarak sanat eserlerinin orijinal ve farklı üretme yönü üzerinde durdukları söylenebilir. Aynı zamanda öğretmen adaylarının sanat ürünlerine yönelik yaklaşım biçimlerinden birinin de bireylerin eser karşısında aldıkları haz şeklinde algıladıkları belirlenmiştir. Bu hazlar, daha çok insanların yiyeceklerden aldıkları tatlara benzetilmiştir. Öte yandan öğretmen adaylarının sanatı 
yaşamın bir parçası olarak algıladıkları belirlenmiştir. Yaşam için su ve kan nasıl gereklilik arz ediyorsa, insanlar için sanatın da böyle bir gereklilik arz ettiği dile getirilmiştir. Bu sonuca benzer bir sonuç Akdeniz ve Çakırcı'nın (2017) "sanat eğitimi” kavramına yönelik yapmış olduğu araştırmalarında ve Kalyoncu'nun (2012), "Sanat eğitimi dersi” kavramına yönelik yapmış olduğu araştırmada görülmüştür. Buradan hareketle insan hayatının olmazsa olmaz unsurlarından birinin de sanat olduğu söylenebilir.

Katılımcıların ifadeleri doğrultusunda oluşturulan temalar ve bu temaların bünyesinde bulunan metaforlar incelendiğinde "sanat" kavramının belirlenen tema ve metaforlarla örtüştüğü söylenebilir. Dolayısıyla öğretmen adaylarının "sanat" kavramını doğru algıladıkları şeklinde yorum yapılabilir. Ancak "sanat" kavramını temel alan çalışmalar sınırlı sayıdadır. Bu bağlamda analiz çeşitliliğini sağlamak adına, öğretmen adaylarının "sanat" kavramına yönelik tutumlarını, düşüncelerini belirleyebilecek çok sayıda nicel veya nitel araştırmalar yapılabilir.

\section{Kaynakça}

Agyeman, C. A. (2015). Artists' perception of the use of digital media in painting (Doctoral dissertation), Ohio University.

Akdeniz, A., \& Çarıkcı, E. Konservatuvar öğrencilerinin 'sanat eğitimi'kavramına ilişkin metaforik algıları. Mustafa Kemal Üniversitesi Sosyal Bilimler Enstitüsü Dergisi, 14(40), 59-85.

Bilge, G. Ö. K., \& Erdogan, T. (2010). Investigation of preservice teachers' perceptions about concept of technology through metaphor analysis. TOJET: The Turkish Online Journal of Educational Technology, 9(2).

Buchanan, J. (2015). Metaphors as two-way mirrors: Illuminating pre-service to in-service teacher identity development. Australian Journal of Teacher Education, 40(10), 3.

Bulut Kılıç, İ., \& Altıntaş, O. (2016). Çağdaş sanatta metaforik düşünce. İdil Sanat ve Dil Dergisi. 20(5), 185-202.

Cameron L (2003). Metaphor in educational discourse. London: Continuum Publishing.

Cameron, L., \& Maslen, R. (2010). Metaphor analysis. Research practice in applied linguistics, social sciences and the humanities. Oakville, CT: Equinox.

Christodoulou, S. P., \& Styliaras, G. D. (2008, September). Digital art 2.0: art meets "web 2.0 trend. In Proceedings of the 3rd international conference on Digital Interactive Media in Entertainment and Arts (pp. 158-165). ACM.

Ekici, G., Gökmen, A., \& Hakan, K. U. R. T. (2014). Öğretmen adaylarının "bilgisayar" kavramı konusundaki bilişsel yapılarının belirlenmesi. Gazi Üniversitesi Gazi Eğitim Fakültesi Dergisi, 34(3).

Eren, A., \& Tekinarslan, E. (2012). Prospective teachers' metaphors: teacher, teaching, learning, instructional material and evaluation concepts. International Journal of Social Sciences \& Education, 3(2).

Geçit, Y. ve Gençer, G. (2011). Sınıf öğretmenliği 1. sınıf öğrencilerinin coğrafya algılarının metafor yoluyla belirlenmesi (Rize Üniversitesi örneği). Marmara Coğrafya Dergisi, (23), 1-19

Hamarat, E. (2016). Capturing pre-service social studies teachers' perceptions about the concept of election through metaphor analysis. Educational Research and Reviews, 11(5), 174.

Hamilton, E. R. (2016). Picture This: Multimodal representations of prospective teachers' metaphors about teachers and teaching. Teaching and Teacher Education, $55,33-44$.

Kalyoncu, R. (2013). Sınıf öğretmeni adaylarının "sanat eğitimi dersi” kavramına ilişkin metaforları. Education Sciences, 8(1), 90-102.

Kilcan, B. (2017). Metafor ve eğitimde metaforik çalışmalar için bir uygulama rehberi. Pegem Akademi, Ankara

Miles, M. B., \& Huberman, A. M. (2015). Nitel veri analizi. Çev. Ed Sadegül Akbaba Altun ve Ali Ersoy). Pegem Akademi: Ankara.

Nartgün, Ş. S., \& Özen, R. (2015). Investigating pedagogical formation students' opinions about ideal teacher, teaching profession, curriculum, responsibility, public personnel selection examination (ppse) and employment: A metaphor study. Procedia-Social and Behavioral Sciences, 174, 2674-2683.

Özsoy, V. (2003). Görsel sanatlar eğitimi: Resim-iş eğitiminin tarihsel ve düşünsel temelleri. Gündüz Eğitim ve Yayıncılik.

Parsons, M. (2010). Interpreting art through metaphors. International Journal of Art \& Design Education, 29(3), 228-235.

Seyitoğlu, F., \& Çakar, K. (2017). Tourism education and internships: a metaphor analysis. Journal of Teaching in Travel \& Tourism, 17(4), 269-280.

Tolstoy, L. (1995). What is art? (R. Pevear and L. Volokhonsky, Trans.). New York, NY: Penguin Books.

Yıldırım. A. ve Şimşek. H. (2013). Sosyal bilimlerde nitel araştırma yöntemleri (9. baskı). Ankara: Seçkin Yayıncılık.

Yılmaz, F., Göçen, S., \& Yılmaz, F. (2013). Öğretmen adaylarının öğretmen kavramına ilişkin algıları: Bir metaforik çalışma. Mersin Üniversitesi Eğitim Fakültesi Dergisi, 9(1). 
